\title{
Surface Ablation Techniques for Myopia - A Review of the Advances Over the Past 25 Years
}

\author{
Jesper Hjortdal \\ Department of Ophthalmology, Aarhus University Hospital NBG, Aarhus, Denmark
}

\section{Keywords}

Photorefractive keratectomy, laser in situ keratomileusis (LASIK), refractive surgical procedures, myopia, excimer laser

Disclosure: Jesper Hjortdal discloses that Aarhus University Hospital has signed a research support agreement with Carl Zeiss Meditec, Jena Germany. No funding was received in the publication of this article. This study involves a review of the literature and did not involve any studies with human or animal subjects performed by any of the authors.

Authorship: All named authors meet the International Committee of Medical Journal Editors (ICMJE) criteria for authorship of this manuscript, take responsibility for the integrity of the work as a whole, and have given final approval to the version to be published.

open Access: This article is published under the Creative Commons Attribution Noncommercial License, which permits any non-commercial use, distribution, adaptation and reproduction provided the original author(s) and source are given appropriate credit.

Received: 21 April 2017

Accepted: 15 June 2017

Citation: European Ophthalmic Review, 2017;11(1):31-4

Corresponding Author: Jesper Hjortdal, Department of Ophthalmology, Building 10, 2nd floor, Aarhus University Hospital NBG, 8000 Aarhus C, Denmark.

E: jesphjor@rm.dk
Photorefractive keratectomy (PRK) is the first laser-based technique that aimed to change the refractive power of the cornea. The principle of excimer laser ablation of the cornea is based on controlled emission of $193 \mathrm{~nm}$ pulses generated from excited dimers of argon fluoride (ArF) gases. When such a gas is put under electrical stimulation and high pressure, the excited compound can give up its excess energy by undergoing spontaneous emission, which very quickly (on the order of a picosecond) dissociates back into two unbound atoms. Directing the emitted light towards, for example, biological materials will result in ablation of surface molecules. In the early 1980s it was shown that using this approach biological materials, including the cornea, could be incised using the excimer laser.1-3 After short time, it was realised that actual surface ablation of the corneal stroma was possible after removal of the corneal epithelium ${ }^{4}$ and that the resulting surface was very smooth..$^{5}$ In 1987, excimer laser-based keratotomy was performed in a human eye, ${ }^{6}$ but it was the surface ablation application that pushed development of excimer lasers. ${ }^{7.8}$ The first preliminary results in human eyes were published the late $1980 \mathrm{~s}^{9-12}$ and excimer lasers became commercially available around 1990. In the early 1990s larger follow-up series of patients undergoing PRK for myopia were published. ${ }^{13-15}$ Since then, many modifications of PRK have been introduced, and a common uniting name for all these techniques is 'surface ablation'. This review will focus on surface ablation for myopia.

\section{Development of excimer lasers}

Directing the location of the excimer laser rays is essential to change the surface shape of the cornea in a controlled way. The first lasers were based on a scanning slit of excimer laser pulses, which was modified by a mechanical aperture built into a suction device. The resulting ablation of the cornea resulted in a stepwise change in the surface shape of the corneal stroma, but these steps were smoothed by the healed corneal epithelium, making a smooth surface and tear film. Simultaneously, wide-field excimer lasers were introduced. These lasers ablated the full diameter of the ablation zone simultaneously, and the change in shape was based on controlling a differential efficiency between central and peripheral rays. After a few years, most excimer lasers became based on using a flying spot of small size, which in a controlled way could reshape the corneal surface into almost any shape. Thus, myopia, hyperopia, astigmatism and even irregular astigmatism could in principle be corrected, if the flying laser spot was controlled properly. Today, all excimer lasers on the market are based on the flying spot principle, but the repetition rate of the lasers vary.

\section{The original surface ablation technique}

Originally, PRK was performed as follows. After topical anaesthesia, the patient was placed on the excimer laser bed, the eye to be treated was draped and a speculum inserted. The corneal epithelium was removed centrally using a spatula. The patient was then asked to look at a central fixation light in the excimer laser, and the eye was manually kept in a steady position using a suction device, and laser ablation was initiated. The diameter of the ablation zone was typically small, often less than $5 \mathrm{~mm} .{ }^{12} \mathrm{After}$ ablation, the eye was treated with antibiotic drops and steroids. The epithelium typically healed within a few days. Over time, development of superficial haze in the 
corneal stroma and regression was often observed in experimental ${ }^{16,17}$ as well as clinical studies. ${ }^{13-15}$ In the early 1990s, clinical accounts from all over the world reported on the use of PRK for myopia. .8,19 $^{1}$

\section{Modifications of the original technique}

It rapidly became clear that after a PRK procedure, most patients developed some haze in the anterior cornea, that considerable regression of treatment was observed over the first several months after surgery, that visual acuity was often disturbed during the night, that treatment of astigmatisms was not possible, and that most patients had considerable pain during the first days after surgery due to healing of the epithelial defect. In subsequent years, refinements of the original technique were investigated to address these issues. Approaches have included surgical, as well as pharmacological modifications.

\section{Pharmacological modifications}

Animal experiments revealed early on that PRK results in considerable changes in the corneal stroma, mainly activation of keratocytes, resulting in haze..$^{16,17}$ Topical steroids were regularly used to reduce the formation of haze, and in animal studies it was also found that the wound healing response could be reduced by topical steroids and mitomycin C (MMC). ${ }^{20}$

\section{Steroids and non-steroidal anti-inflammatory drugs}

Early on, it was shown in prospective randomised trials that the use of topical steroids only, for a limited time, could reduce refractive regression but could not reduce haze.21-23 Observational studies have, however, shown some beneficial effect of topical steroids in patients treated with PRK for high myopia. ${ }^{24}$ One study has shown that postoperative topical diclofenac and dexamethasone used during the first 3 days following PRK may negatively affect epithelial healing and early visual rehabilitation. ${ }^{25}$ Another randomised study indicated, however, that steroid eyedrops administered in the first days after PRK did not affect re-epithelialisation time, and that fluorometholone drops reduced haze and regression compared with keratolac drops, whereas keratolac was more efficient to reduce pain in the first few days after surgery. ${ }^{26}$

\section{Mitomycin C}

MMC is used as an anti-mitotic agent in cancer therapy, but has widely been employed in eye surgery to reduce scar formation after pterygium surgery, and in the last 15 years it has also been used after PRK. In highly myopic eyes randomised to PRK with or without MMC, topical intraoperative application of $0.02 \% \mathrm{MMC}$ may reduce haze formation. ${ }^{27}$ In a prospective contralateral study of PRK, PRK with MMC (MMC-PRK) and laser subepithelial keratomileusis (LASEK) in moderate and high myopia, the MMC-PRK group showed some benefits in minimising corneal haze formation. One year after surgery, there was no discernible difference in the postoperative refractive outcomes among the three methods. ${ }^{28}$ Similarly, a prospective randomised controlled study showed MMC may not be needed to prevent haze after modern PRK with a four-month steroid taper. There was no clinically significant difference in haze formation between MMC eyes and control eyes at the concentration and exposures used..$^{29}$ In 2015, the American Academy of Ophthalmology concluded that there is good evidence of the effectiveness of MMC when used intraoperatively as prophylaxis against haze in higher myopic ablations. ${ }^{30}$

\section{Reducing pain}

During healing, the epithelial defect arising after PRK causes much pain. In an effort to ease the pain during the postoperative period for patients, therapeutic contact lenses are effective, as shown in a prospective randomised study. ${ }^{31}$ Topical non-steroidal anti-inflammatory drugs
(NSAIDS) in the form of keratolac $0.4 \%$ four times daily for 4 days has also been shown to be effective and safe, ${ }^{32}$ while the addition of topical diclofenac to patients receiving systemic diclofenac is ineffective..$^{33}$ In a prospective, randomised study, the addition of gabapentinoids to standard systemic NSAID-based painkillers seems to have some effect on post-PRK pain. ${ }^{34}$

\section{Surgical modifications}

The presence of an epithelial defect causes pain and results in free access for inflammatory mediators from the tear film to the corneal stroma. A logical approach, therefore, was to develop a surgical technique to promote fast re-epithelialisation and formation of a biological barrier of the denuded stroma to reduce haze, regression and pain. LASEK, epipolis laser in situ keratomileusis (Epi-LASIK) and transepithelial ablation are examples of such techniques.

\section{Laser subepithelial keratomileusis}

Traditionally, the central corneal epithelium was removed and discarded by scraping, which was often made easier when assisted by alcohol. In LASEK, the epithelium is loosened by controlled application of a $20 \%$ alcohol application for 20 seconds. The epithelium is then gently pushed away and saved at the margin of the denuded stroma to be treated. After ablation, the epithelial sheet is repositioned and a therapeutic contact lens is applied. It was believed that the firm presence of a biological contact lens in the form of the re-positioned epithelium could reduce haze formation and promote re-epithelialisation. The technique was introduced in 2001. ${ }^{35}$ Since then, it has been realised in randomised studies that the technique is not superior to conventional PRK in terms of patient comfort, reduction of haze or regression. ${ }^{28}$ It seems that the manipulation of the epithelium would leave non-surviving cell and that the biological barrier of the replaced epithelial cells is insufficient to reduce a wound-healing response.

\section{Epipolis laser in situ keratomileusis}

To overcome the necessity for alcohol-assisted epithelial cell removal associated with detrimental cell death, Epi-LASIK was introduced. ${ }^{36}$ The technique uses a blunt microkeratome blade to simply scrape the epithelium away, and following laser ablation, the cell sheet is replaced and covered by a therapeutic contact lens. Studies have documented that even mechanical scraping of cells result in cell death and studies have also shown that it does not matter in terms of haze development and regression whether the cell sheet is replaced ('epi-on') or not ('epioff'). ${ }^{37}$ The placement of a therapeutic bandage contact lens will, however, reduce postoperative pain.

\section{Trans-epithelial photorefractive keratectomy}

Direct removal of the corneal epithelium using excimer laser pulses makes surface ablation even easier. ${ }^{38-40}$ In patients with stromal dystrophies or irregular astigmatism, the epithelium may serve as a fine smoothing agent in phototherapeutic keratectomy. ${ }^{38}$

\section{Laser ablation algorithms}

The first ablation algorithms were based on the Munnerlyn formula, ${ }^{41}$ which was a spherical algorithm. As the diameter of the ablation zones in early lasers was small, many patients experienced considerable night vision disturbances when the pupil was larger. During the 1990s, larger ablation zones could be created, and aspherical (wavefront optimised) ablation profiles were developed. These factors reduced night vision disturbances. With the introduction of interfaces between topographers and aberrometers, it became possible to individualise laser ablations as topography ${ }^{42}$ or wavefront-guided treatments. It has, however, been 
difficult to document a clear advantage of wavefront-guided treatments over wavefront-optimised treatments. ${ }^{43}$

\section{Summary of meta-analyses related to comparison of different surface ablation techniques and laser in situ keratomileusis}

Hundreds of papers comparing clinical results after the many variations of surface ablation techniques have been published and surface ablation procedures have been compared with LASIK. Many papers are based on retrospective comparisons, few are prospective, and even fewer are randomised controlled trials (RCTs). Several meta-analyses have been published in recent years, and the results from these are summarised below.

The effectiveness and safety of PRK and LASIK for correction of myopia have been studied in meta-analyses published in 2006 and 2013. ${ }^{44,45}$ The main conclusions are that LASIK gives a faster visual recovery and is a less painful technique than PRK. The two techniques appear to give similar outcomes one year after surgery, but further trials using contemporary techniques are required to determine whether LASIK and PRK as currently practiced are equally safe. In another recent meta-analysis comparing LASEK with LASIK, ${ }^{46}$ it was also concluded that overall, from the available RCTS, there is uncertainty in how LASEK compares with LASIK in achieving better refractive and visual results in mildly to moderately myopic participants. Large, well-designed RCTs would be required to estimate the magnitude of any difference in efficacy or adverse effects between LASEK and LASIK for treating myopia or myopic astigmatism.

In a meta-analysis comparing epithelial flap 'off' versus 'on' after EpiLASIK, ${ }^{47}$ it was concluded that the two techniques had equal visual and refractive outcomes for the treatment of myopia. Off-flap Epi-LASIK had more rapid re-epithelialisation and visual recovery compared to on-flap Epi-LASIK.
In a meta-analysis comparison of LASIK and Epi-LASIK for myopia, there were no significant differences in efficacy, predictability, safety, epithelial healing time and corneal haze formation between the techniques. ${ }^{48}$

A recent meta-analysis comparing LASEK and conventional PRK ${ }^{49}$ concluded that uncertainty surrounds differences in efficacy, accuracy, safety and adverse effects between LASEK and PRK for eyes with low to moderate myopia. A similar conclusion was reached and published in $2010 .{ }^{50}$

Most recently, a network-based meta-analysis comparing the postoperative efficacy, predictability, safety and visual quality of all major forms of laser corneal refractive surgeries (PRK, LASEK, Epi-LASIK, trasepithelial PRK, LASIK, femtosecond assisted [FS-LASIK], small incision lenticule extraction and femtosecond lenticule extraction) for correcting myopia was published. ${ }^{51}$ Based on analysis of 48 RCTS, the authors concluded that this network meta-analysis showed that there were no statistically significant differences in both visual outcomes (efficacy and safety) and visual quality (higher-order aberrations and contrast sensitivity) between the techniques. FS-LASIK behaved better in predictability than any other type of surgery.

\section{Conclusions}

The results after surface ablation of the cornea for correction of refractive errors have improved since PRK was introduced in 1990. The improvements are mainly due to technological perfection of the excimer lasers with respect to optimising the ablation profiles and eye-tracking during treatment. There seem to be no differences between the clinical results obtained with the different variations of surface ablation techniques. The use of haze-reducing pharmacological agents such as MMC peri-operatively and topical steroids postoperatively possibly should be restricted to eyes with scars and those which have undergone previous refractive or corneal surgery. $\mathrm{u}$
1. Trokel SL, Srinivasan R, Braren B, Excimer laser surgery of the cornea, Am J Ophthalmol, 1983:96:710-5.

2. Renard G, Hanna K, Saragoussi JJ, Pouliquen Y, Excimer laser experimental keratectomy. Ultrastructural study, Cornea, 1987;6:269-72.

3. Marshall J, Trokel S, Rothery S, Krueger RR, A comparative study of corneal incisions induced by diamond and steel knives and two ultraviolet radiations from an excimer laser, $\mathrm{Br} J$ Ophthalmol, 1986;70:482-501

4. Missotten L, Boving R, François G, Coutteel C, Experimental excimer laser keratomileusis, Bull Soc Belge Ophtalmol 1986;220:103-20

5. Kerr-Muir MG, Trokel SL, Marshall J, Rothery S, Ultrastructural comparison of conventional surgical and argon fluoride excimer laser keratectomy, Am J Ophthalmol, 1987;103(3 Pt 2):448-53.

6. Aron-Rosa DS, Boerner CF, Bath P, et al., Corneal wound healing after excimer laser keratotomy in a human eye, $\mathrm{Am}$ Ophthalmol, 1987;103(3 Pt 2):454-64.

7. Schröder E, Dardenne MU, Neuhann T, Tenner A, An ophthalmic excimer laser for corneal surgery, Am J Ophthalmol, 1987,103. Pt 2):472-3.

8. Hanna K, Chastang JC, Pouliquen $Y$, et al., A rotating slit delivery system for excimer laser refractive keratoplasty, Am J Ophthalmol, 1987:103(3 Pt 2):474.

9. L'Esperance FA Jr, Taylor DM, Del Pero RA, et al., Human excimer laser corneal surgery: preliminary report, Trans Am Ophthalmol Soc, 1988;86:208-75.

10. MCDonald MB, Kaufman HE, Frantz JM, et al., Excimer laser ablation in a human eye. Case report, Arch Ophthalmol, 1989;107:641-2

11. Taylor DM, L'Esperance FA Jr, Del Pero RA, et al., Human excimer laser lamellar keratectomy. A clinical study, Ophthalmology, 1989:96:654-64.

12. MCDonald MB, Frantz JM, Klyce SD, et al., Central photorefractive keratectomy for myopia. The blind eye study, Arch Ophthalmol, 1990:108:799-808.

13. Dausch D, Klein R, Schröder E, [Photoablative, refractive keratectomy in treatment of myopia. A case study of 134 myopic eyes with 6-months follow-up] (in German), Fortschr ophthalmol, 1991:88:770-6.

14. Lindstrom RL, Sher NA, Chen V, et al., Use of the 193-NM excimer laser for myopic photorefractive keratectomy in sighted eyes: a multicenter study, Trans Am Ophthalmol Soc 1991;89:155-72.
15. Seiler T, Wollensak J, Myopic photorefractive keratectomy with the excimer laser. One-year follow-up, Ophthalmology, 1991;98:1156-63

16. Cintron C, Corneal epithelial and stromal reactions to excimer laser photorefractive keratectomy. II. Unpredictable corneal cicatrization, Arch Ophthalmol, 1990;108:1540-1.

17. Del Pero RA, Gigstad JE, Roberts AD, et al., A refractive and histopathologic study of excimer laser keratectomy in primates, Am J Ophthalmol, 1990:109:419-29.

18. Lawless MA, Cohen P, Rogers $C$, Excimer laser photorefractive keratectomy: first Australian series, Med J Aust, 1992;156:812.

19. Ehlers N, Hjortdal JO, Excimer laser refractive keratectomy for high myopia. 6-month follow-up of patients treated bilaterally, Acta Ophthalmol (Copenh), 1992;70:578-86

20. Talamo JH, Gollamudi S, Green WR, et al., Modulation of corneal wound healing after excimer laser keratomileusis using topical mitomycin C and steroids, Arch Ophthalmol, 1991;109:1141-6.

21. Gartry DS, Muir MG, Lohmann CP, Marshall J, The effect of topical corticosteroids on refractive outcome and corneal haze after photorefractive keratectomy. A prospective, randomized, double-blind trial, Arch Ophthalmol, 1992;110:944-52.

22. O'Brart DP , topical corticosteroids and plasmin inhibitors on refractive outcome, haze, and visual performance after photorefractive outcome, haze, and visual performance after photorefractive
keratectomy. A prospective, randomized, observer-masked keratectomy. A prospective, randomized,
study, Ophthalmology, 1994:101:1565-74.

23. Aras C, Ozdamar A, Aktunç R, Erçikan C, The effects of topical steroids on refractive outcome and corneal haze, thickness, and curvature after photorefractive keratectomy with a 6.0-mm ablation diameter, Ophthalmic Surg Lasers, 1998:29:621-7.

24. Baek SH, Chang JH, Choi SY, et al., The effect of topical corticosteroids on refractive outcome and corneal haze after photorefractive keratectomy, J Refract Surg, 1997:13:644-52

25. Tomas-Barberan S, Fagerholm P, Influence of topical treatment on epithelial wound healing and pain in the early postoperative period following photorefractive keratectomy, Acta Ophthalmo Scand, 1999:77:135-8.

26. Vetrugno M, Maino A, Quaranta GM, Cardia L, The effect of early steroid treatment after PRK on clinical and refractive outcomes, Acta Ophthalmol scand, 2001;79:23-7.

27. Gambato C, Ghirlando A, Moretto E, et al., Mitomycin C modulation of corneal wound healing after photorefractive keratectomy in highly myopic eyes, ophthalmology 2005;112:208-18.
28. Sia RK, Ryan DS, Edwards JD, et al., The U.S. Army Surface Ablation Study: comparison of PRK, MMC-PRK, and LASEK in moderate to high myopia, J Refract Surg, 2014;30:256-64.

29. Hofmeister EM, Bishop FM, Kaupp SE, Schallhorn SC, Randomized dose-response analysis of mitomycin-C to prevent haze after photorefractive keratectomy for high myopia J Cataract Refract Surg, 2013;39:1358-65.

30. Majmudar PA, Schallhorn SC, Cason JB, et al., Mitomycin-C in corneal surface excimer laser ablation techniques: a report by the American Academy of Ophthalmology, Ophthalmology, 2015;122:1085-95

31. Lim-Bon-Siong R, Valluri S, Gordon ME, Pepose IS, Efficacy and safety of the ProTek (Vifilcon A) therapeutic soft contact lens after photorefractive keratectomy, Am I Ophthalmol, 1998;125:169-76

32. Solomon KD, Donnenfeld ED, Raizman M, et al., Ketorolac Reformulation Study Groups 1 and 2. Safety and efficacy of ketorolac tromethamine $0.4 \%$ ophthalmic solution in postphotorefractive keratectomy patients, I Cataract Refract Surg, 2004;30:1653-60.

33. Eslampoor A, Ehsaei A, Abrishami M, Effect of topical diclofenac on postoperative photorefractive keratectomy pain: a randomized, controlled trial, Clin Exp Ophthalmol, 2014:42:810-4

34. Meek JM, Rosbolt MB, Taylor KR, et al., Pregabalin versus placebo in postoperative pain relief of patients' status post photorefractive keratectomy: a double-masked, randomized, prospective study, J Ocul Pharmacol Ther, 2014;30:527-32

35. Azar DT, Ang RT, Lee JB, et al., Laser subepithelial keratomileusis: electron microscopy and visual outcomes of flap photo- refractive keratectomy, Curr Opin Ophthalmol 2001;12:323-28

36. Pallikaris IG, Katsanevaki VJ, Kalyvianaki MI, Naoumidi II Advances in subepithelial excimer refractive surgery techniques: Epi-LASIK, Curr Opin Ophthalmol, 2003;14:207-12

37. Taneri S, Oehler S, Koch J, Azar D, Effect of repositioning or discarding the epithelial flap in laser-assisted subepithelia keratectomy and epithelial laser in situ keratomileusis, J Cataract Refract Surg, 2011;37:1832-46.

38. Kapadia MS, Wilson SE, Transepithelial photorefractive keratectomy for treatment of thin flaps or caps after complicated laser in situ keratomileusis, Am J Ophthalmol 1998;126:827-9. 
39. Stojanovic A, Chen S, Chen X, et al., One-step transepithelial topography-guided ablation in the treatment of myopic . 2013:8:e66618.

40. Aslanides IM, Kymionis GD, Trans advanced surface laser ablation (TransPRK) outcomes using SmartPulseTechnology, Cont Lens Anterior Eye, 2017:40:42-46.

41. Munnerlyn CR, Koons SJ, Marshall J, Photorefractive keratectomy: a technique for laser refractive surgery, $J$ Cataract Refract Surg, 1988;14:46-52.

42. Hjortdal Jø, Ehlers N, Treatment of post-keratoplasty astigmatism by topography supported customized laser ablation, Acta Ophthalmol Scand, 2001;79:376-80.

43. Ryan DS, Sia RK, Stutzman RD, et al., Wavefront-Guided Versus Wavefront-Optimized Photorefractive Keratectomy: Visual and Military Task Performance, Mil Med, 2017:182:e1636-01644.
44. Shortt AJ, Allan BD, Photorefractive keratectomy (PRK) versus laser-assisted in-situ keratomileusis (LASIK) for myopia, Cochrane Database Syst Rev, 2006:2:CD005135.

45. Shortt AJ, Allan BD, Evans JR, Laser-assisted in-situ keratomileusis (LASIK) versus photorefractive keratectomy (PRK) for myopia, Cochrane Database Syst Rev,

2013;1:CD005135

46. Kuryan J, Cheema A, Chuck RS, Laser-assisted subepithelia keratectomy (LASEK) versus laser-assisted in-situ keratomileusis (LASIK) for correcting myopia, Cochrane Database Syst Rev, 2017;2:CD011080

47. Feng $\mathrm{YF}$, Chen $\mathrm{SH}$, Stojanovic $\mathrm{A}$, Wang $\mathrm{QM}$, Comparison of clinical outcomes between 'on-flap' and 'off-flap' epi-LASIK for myopia: a meta-analysis, Ophthalmologica, 2012;227:45-54.

48. Wen D, Huang J, Li X, et al., Laser-assisted subepithelia keratectomy versus epipolis laser in situ keratomileusis for myopia: a meta-analysis of clinical outcomes, Clin Exp Ophthalmol, 2014:42:323-33

49. Li SM, Zhan S, Li SY, et al., Laser-assisted subepithelia keratectomy (LASEK) versus photorefractive keratectomy (PRK) for correction of myopia, Cochrane Database Syst Rev 2016;2:CD00979

50. Zhao LQ, Wei RL, Cheng JW, et al., Meta-analysis: clinical outcomes of laser-assisted subepithelial keratectomy an photorefractive keratectomy in myopia, Ophthalmology, 2010;117:1912-22.

51. Wen D, McAlinden C, Flitcroft I, et al., Post-operative efficacy, predictability, safety and visual quality of laser corneal refractive surgery: a network meta-analysis, Am J Ophthalmo , 2017;178:65-78. 